\title{
Preconceito, Discriminação e Cidadania LGBT: Políticas Públicas em Mato Grosso e no Brasil
}

\author{
Henrique Araújo Aragusuku \\ Graduado em Psicologia/ UFMT \\ Moisés Lopes \\ Departamento de Antropologia \\ Programa de Pós-Graduação em Antropologia Social/UFMT
}

Resumo: Este texto é baseado em uma pesquisa científica desenvolvida entre os anos de 2011 e 2014, e congrega resultados de análises tendo como objetivo apresentar um levantamento das políticas públicas para a população LGBT no Estado de Mato Grosso, relacionando-as com as principais políticas públicas no Brasil. Esse levantamento é acompanhado por uma análise geral, trazendo reflexões sobre Estado e sociedade civil, políticas públicas e cidadania LGBT, proporcionando uma análise crítica sobre como tais políticas vêm se efetivando, quais os empecilhos, os avanços e as perspectivas para um estado no interior do país que apresenta altos índices de preconceito, discriminação e assassinatos de LGBT e uma imensa fragilidade na construção de políticas eficazes de promoção de direitos e cidadania para essa população.

Palavras-chave: políticas públicas, discriminação, cidadania, LGBT, Mato Grosso. 


\title{
Prejudice, Discrimination and LGBT Citizenship: Public Policies in Mato Grosso and Brazil
}

\begin{abstract}
This text is based on a scientific research developed between the years of 2011 and 2014, and it brings together analysis results aiming to present a survey of the public policies for the LGBT population in the State of Mato Grosso, relating them to the main public policies in Brazil. This survey is accompanied by a overview bringing reflections about State and civil society, public policies and LGBT citizenship, providing a critical analysis of how such policies have been effective applied, what are the obstacles, advances and prospects for a state of the countryside with high rates of prejudice, discrimination and murders of LGBT and a huge weakness in building effective policies in the promotion of rights and citizenship to this population.
\end{abstract} Grosso

Keywords: public policies, discrimination, citizenship, LGBT, Mato

\section{Prejuicio, Discriminación and Ciudadanía LGBT: Políticas Públicas en Mato Grosso y Brasil}

Resumen: Este texto se basa en una investigación científica desarrollada entre los años de 2011 y 2014, y reúne los resultados de análisis con el objetivo de presentar un estudio de las políticas públicas para la población LGBT en el Estado de Mato Grosso, relacionándolos con las principales políticas públicas en Brasil. Esta encuesta se acompaña de un análisis general, trayendo reflexiones sobre el Estado y la sociedad civil, las políticas públicas y ciudadanía LGBT, proporcionando un análisis crítico de cómo tales políticas vienen efectivandose, qué obstáculos los avances y las perspectivas de un estado en el interior del país que presenta altos niveles de prejuicio, discriminación y asesinatos de LGBT y una enorme debilidad en la construcción de políticas efectivas de promoción de derechos y ciudadanía para esta población.

Palabras-clave: políticas públicas, discriminación, ciudadanía, LGBT, Mato Grosso. 


\section{Introdução}

As políticas públicas voltadas para gays, lésbicas, travestis, bissexuais, e homens e mulheres transexuais (LGBT), seja de combate à discriminação ou de atendimento as especificidades desse grupo social, são marcadas no Brasil por imensas fragilidades e marcante instabilidade. É inegável que nas duas últimas décadas tivemos grandes avanços, com o reconhecimento de parte significativa do poder público brasileiro da necessidade de implementação de políticas e direitos LGBT. Entretanto, vivemos atualmente um cenário de avanço do conservadorismo político no Brasil, que se reflete na eleição do Congresso Nacional mais conservador desde a redemocratização do país (DEPARTAMENTO INTERSINDICAL DE ASSESSORIA PARLAMENTAR, 2014), no avanço do fundamentalismo religioso nas instituições políticas e, inclusive, na rearticulação dos movimentos de extrema-direita que retornaram à luz após décadas, principalmente na composição das manifestações de 2014 e 2015 pelo impeachment da presidente do país. Também vivemos um momento de forte crise econômica que afeta diretamente as finanças do Estado, em que o Governo Federal e os Governos Estaduais, acatando as normativas neoliberais, aplicam uma agenda de redução dos gastos públicos e de desmonte das políticas sociais, junto a ampliação das privatizações e terceirizações nos serviços públicos.

O atual cenário político é de estreitamento da agenda política LGBT, e apesar de presenciarmos marcantes avanços em algumas localidades - como o orçamento de $\mathrm{R} \$$ 8,8 milhões da Coordenação de Políticas para a Diversidade Sexual da cidade de São Paulo, em 2016 - temos também retrocessos históricos, como o desmonte do Programa Rio Sem Homofobia, no Estado do Rio de Janeiro. O Rio Sem Homofobia, programa estadual considerado um modelo de promoção de direitos LGBT, teve mais de $75 \%$ de seu quadro de funcionários demitido, parando as atividades de seus quatro Centros de Cidadania no início de 2016. Atualmente, o Rio de Janeiro passa por uma das maiores crises orçamentarias de sua história, atingindo principalmente os serviços públicos de saúde e educação, sendo utilizada para justificar o desmonte do Rio Sem Homofobia. Porém, o Secretário Estadual de Direitos Humanos, naquele período, era nada menos que o pastor ultraconservador Ezequiel (PMB/RJ), Deputado Federal eleito em 2014 com uma campanha que associava os movimentos LGBT à pedofilia e à destruição da família.

Assim, algo que já vem sendo apontado há anos por pesquisadoras(es) sobre políticas públicas LGBT no Brasil (CARRARA; VIANA, 2008; MELO; MAROJA; 2010; ITABORAHY, 2012) continua presente, ou mesmo se agrava nos tempos atuais: a implementação de políticas públicas LGBT estão a mercê da "vontade" dos governantes e a negociatas políticas, executadas a partir de frágeis ações do poder executivo e contando com pouquíssimo, ou praticamente nenhum, apoio do poder legislativo. Essa realidade pode ser generalizada para todo o país, tanto em âmbito municipal, estadual e federal. Entretanto, não negamos avanços em diversas regiões, principalmente com a expansão dos conselhos em uma diversidade de Estados e municípios, e podemos apontar que o cenário mais amplo é de um avanço lento e gradual das políticas públicas LGBT, não marcado pela linearidade e sujeito a recuos e embargos. Ou seja, 
presenciamos fortes retrocessos, mas as políticas LGBT entraram na agenda pública de forma irreversível.

Nosso objetivo nesse artigo é, sem nos desprendermos desse cenário mais amplo, levantar de forma mais aprofundada a história das políticas e direitos LGBT no Estado de Mato Grosso, trazendo também elementos das políticas nacionais. É comum a utilização dos acontecimentos ocorridos ao redor de grandes centros metropolitanos, principalmente do eixo Sul-Sudeste, como parâmetro de análises nacionais, produzindo a invisibilização de outras realidades regionais do Brasil. É fato que as primeiras políticas públicas LGBT se desenvolveram basicamente em metrópoles do eixo Sul-Sudeste, entretanto, nos últimos dez anos tais políticas se expandiram e se consolidaram em diversas regiões do país, e para falarmos de políticas LGBT no Brasil devemos levar em conta a diversidade regional desse país de tamanho continental.

O desenvolvimento teórico-metodológico presente nesse artigo foi realizado no âmbito do projeto de pesquisa intitulado "Homossexualidades, Preconceitos e Discriminações: A construção social do gênero no universo LGBT da baixada cuiabana", que foi financiada pelo Programa de Infraestrutura para Jovens Pesquisadores (Programa Primeiros Projetos), Edital PPP 002/2012, desenvolvido pelo MCT/CNPq/FAPEMAT, durante o período de 2011 a 2014. Foram levantadas produções acadêmicas relaciona a temáticas como Estado e políticas públicas, políticas de diversidade sexual e de gênero, movimentos LGBT, buscando também o levantamento de documentos oficiais (como projetos legislativos, pronunciamentos públicos, programas, decretos governamentais, entre outros), além de notícias e publicações vinculadas em portais virtuais.

O Estado de Mato Grosso possui altos níveis de violência e discriminação contra a população LGBT, assim como apresenta grandes dificuldades para a implementação de políticas e ampliação de direitos para esse grupo social. Nos últimos dois anos, Cuiabá esteve na lista de capitais mais perigosas para a população LGBT, de acordo com os relatórios do Grupo Gay da Bahia sobre assassinatos de pessoas LGBT no Brasil. Não são poucos os casos de assassinatos de travestis e transexuais marcados por grande violência, sendo apenas a ponta do iceberg das violações sofridas cotidianamente em decorrência do preconceito e da discriminação. O desenvolvimento dessa análise é também parte de um esforço maior para a construção de estratégias de superação dessa realidade, assim como um espaço de reflexão sobre os desafios e as dificuldades de implementação de políticas LGBT em localidades em que as forças políticas conservadoras possuem uma forte hegemonia sobre o poder público e grande parte da sociedade civil.

Em 2015, foram duas grandes derrotas em casas legislativas de Mato Grosso, que se tornaram marcantes por conta da pressão de grupos organizados de católicos e evangélicos para a desaprovação de políticas LGBT: a remoção de qualquer menção à gênero e diversidade sexual no plano de educação de Cuiabá, na onda das manifestações contra a "ideologia de gênero" nas escolas, e a derrubada do decreto governamental que instituía o Conselho Estadual LGBT. Na votação do Plano Municipal de Educação de Cuiabá, no dia 23 de junho de 2015, participaram alguns manifestantes dos movimentos LGBT locais que, no entanto, eram minoria, sendo esmagados pela multidão que acompanhou a sessão na Câmara de Vereadores. A câmara retirou, por unanimidade, as referências à gênero e diversidade sexual do Plano Municipal de Educação, sob 
pressão de grande manifestação, organizada principalmente pela Igreja Católica, contra a "ideologia de gênero" e pelo direito de famílias educarem "meninos a serem meninos e as meninas serem meninas".

O campo das políticas sexuais em Mato Grosso está sendo fortemente disputado pelo conservadorismo político, que aperfeiçoou nacionalmente seu discurso e suas táticas de enfrentamento político, propagando que as formas de pensar que consideram o gênero e a sexualidade enquanto construções socioculturais são ideológicas e falsas, enquanto as noções cristãs e nossas regras culturais cis-heterossexistas1 são tidas como naturais e verdades absolutas. São evocadas também noções como democracia e liberdade, ou seja, o direito da maioria esmagar a minoria pelo voto, e da liberdade das famílias educarem (ou obrigarem) seus filhos e suas filhas a serem heterossexuais e cisgêneros.

Infelizmente, esta é a arena política da maioria das cidades brasileiras e apresento de forma sintética tais posicionamentos a partir do pronunciamento do Deputado Federal Victório Galli (PSC/MT) na Câmara dos Deputados, de março de 2016, contra a realização da $3^{\text {a }}$ Conferência Estadual LGBT, sendo também apresentado em reunião particular diretamente ao Governador do Estado de Mato Grosso:

\begin{abstract}
Devemos trabalhar para todos os cidadãos, sejam negros, brancos, pardos, amarelos, heterossexuais ou por liberdade de escolha homossexuais. Mas tenho deixado bem claro meu posicionamento em atuar contra o ativismo ideológico gay. Não sou contra pessoas, não sou contra a igualdade de direitos de todo cidadão brasileiro, que já é garantida constitucionalmente, seja qual for sua opção sexual. Pois cada um faz de sua vida o que bem entender, desde que não fira os direitos individuais de outros. Porém, ressalto minha posição contrária ao ativismo ideológico gay, que busca privilégios políticos e atua de forma incansável para atingir nossa próxima geração, isso mesmo, nossas crianças com suas posições ditas progressistas, atropelando o papel e dever, social e cívico dos pais em educarem seus filhos (BRASIL, 2016, grifos nossos).
\end{abstract}

\title{
Estado, Políticas Sexuais e Cidadania LGBT
}

O gênero e a sexualidade são construções históricas e sociopolíticas (FOUCAULT, 1988; SCOTT, 1986; WEEKS, 2002), sendo noções instrumentalizadas em nossa sociedade para se apresentarem enquanto um dado natural, rígido e imutável. A naturalização da heterossexualidade e da cisgeneridade enquanto únicas formas legítimas de expressões humanas dão as bases para a supressão das sexualidades desviantes (WELZER-LANG, 2001), que se expressa tanto pela violência simbólica quanto pela repressão e pelo extermínio. Logo, a produção de hierarquias de valor sexual institui quais sexualidades são superiores e legítimas, enquanto as pessoas que estão nos níveis mais baixos da hierarquia sexual estão "sujeitas a presunções de doença mental, má reputação, criminalidade, restringidas em sua mobilidade física e social, perda de suporte institucional, e sanções econômicas" (RUBIN, 1984, p. 151, tradução nossa).

Como apresenta Jeffrey Weeks (2002), "a sexualidade, como um fenômeno contemporâneo, é o produto de uma série de tradições autônomas e em interação: religiosas, morais, econômicas, familiares, médicas, jurídicas" (p.

1 O termo "cis" está inserido dentro de um complexo debate sobre identidade de gênero. De forma simplificada, se refere às pessoas que não são trans, que são vistas por nossa sociedade como "naturais/normais", pois estão em confluência com identidade de gênero exigida para determinada genitália (ex. pênis=homem). 
6, tradução nossa), não podendo ser resumida à uma única relação, sendo sobretudo um campo em disputa e em constante transformação. Ao longo do final do século XIX e início do século XX, tivemos mudanças significativas na estrutura das sociedades da Europa Ocidental e da América do Norte que possibilitaram o surgimento dos primeiros movimentos em defesa das homossexualidades e a disputa de um espaço, até aquele momento, unicamente repressor das sexualidades não cis-heterossexuais: as políticas do Estado.

A repressão estatal às sexualidades desviantes não é um fenômeno recente na história da cultura ocidental. A incorporação do cristianismo pelo Império Romano marca a assimilação estatal da moral judaico-cristã e da natureza superior das relações heterossexuais e monogâmicas, resultando na implementação de códigos, já no século IV, que condenavam à fogueira as pessoas que praticassem atos homossexuais (BORRILLO, 2010). Ao final do século XIX, a condenação estatal das homossexualidades era recorrente em todos os dos países do mundo, e apesar de mudanças nesse cenário, ainda há um número significativo de países que persistem com severas condenações contra práticas homossexuais.

Para uma análise sobre o Estado contemporâneo, utilizamos a noção de Estado ampliado, desenvolvida pelas formulações políticas de Antonio Gramsci (COUTINHO, 2000, 2008; COSTA; SIMIONATTO, 2012), se distanciando das leituras que resumem o Estado e suas políticas unicamente a partir de seu aparelho jurídico-administrativo e militar-repressor. Nessa linha, o Estado não é um bloco monolítico, mas uma complexa e delicada rede de instituições e relações de poder, sendo "uma síntese contraditória e dinâmica entre sociedade política e sociedade civil" (COUTINHO, 2000, p. 22). Os Estados contemporâneos, na qual se inclui o Estado brasileiro, manifestam a supremacia de determinados grupos sociais, tanto pela hegemonia (consenso), na esfera da sociedade civil, quanto pela dominação (coerção), no campo da sociedade política. Definindo esses dois campos, a sociedade política:

\footnotetext{
(...) comumente definida como sendo o próprio Estado, Estado em sentido estrito ou Estado-coerção a serviço da classe dominante, representando o monopólio legal da repressão e da violência sob o controle das burocracias executivas e policial-militar. Já a segunda, a sociedade civil, compreende o conjunto das organizações responsáveis pela construção e disseminação das ideologias: os partidos políticos, os sindicatos, as organizações profissionais, a organização material da cultura, o sistema escolar, os movimentos sociais, dentre outras (COSTA; SIMIONATTO, 2012: 14).
}

Assim, o Estado não é uma burocracia neutra, mas uma síntese das disputas políticas que estão presentes em nossa sociedade. As fronteiras entre Estado e sociedade civil, entre as esferas do público e do privado, são bastante delicadas e comumente porosas, marcadas por relações híbridas. Não podemos negar a existência de relativa autonomia das diferentes esferas e instituições do Estado e da sociedade civil, entretanto não se trata de relação de independência, mas de interdependência. Trazendo outros elementos para nossa análise, tal como aponta Michael Herzfeld (1997), o Estado é um conjunto aberto de agentes e operações, possuindo como ponto de equilíbrio a limitação, essencialização e naturalização de experiências sociais múltiplas e polifônicas com o intuito de produção e manipulação da realidade social. Ao longo da história, as políticas sexuais foram campo privilegiado de controle e manipulação estatal na busca da manutenção e institucionalização das desiguais relações de poder em nossa sociedade (CONNELL, 1990). 
A noção de direitos humanos, que nasce nas lutas burguesas pela derrubada do absolutismo feudal, possibilita a constituição de novas relações político-estatais, sendo o Estado responsável pela preservação de direitos universais, baseados na filosofia liberal (IRINEU, 2014). A constituição da sociedade civil e da cidadania liberal, ao final do século XVIII, possibilita a abertura do Estado - ainda que parcial e em constante tensionamento - para as lutas políticas de grupos sociais organizados. As transformações desencadeadas pela emergência da classe trabalhadora e pelas lutas políticas possibilitaram mudanças nas relações entre Estado e sociedade, que de acordo com a tese de T. H. Marshall (1992), passaram pela conquista dos direitos cidadãos, nos séculos XVIII e XIX, aos direitos políticos no final do século XIX, e por fim à constituição dos direitos sociais, no século XX. A instituição dos direitos sociais e a consolidação da noção de direitos humanos, tendo como marco a proclamação da Declaração Universal dos Direitos Humanos, em 1948, pela Organização das Nações Unidas - na esteira da crise mundial de 1929, das atrocidades da Segunda Guerra Mundial e do avanço do comunismo soviético como modelo socioeconômico alternativo - atribuíram como responsabilidade dos Estados a promoção de bem-estar social, a garantia das liberdades e da segurança pessoal, junto a não discriminação a qualquer grupo social. Assim, após a Segunda Guerra, se constitui o paradigma do Estado de Bem-Estar Social, responsável pela promoção universal de direitos sociais - como saúde e educação - e pela regulação das desigualdades econômicas (BEHRING, 2006).

Entretanto, a garantia de direitos sociais e humanos de forma universal se fez impossível em um mundo de desiguais relações de poder, sendo uma noção baseada na ideia essencialista de um "sujeito universal": europeu, branco, homem e heterossexual (IRINEU, 2014). Neste sentido, os Estados capitalistas estavam (e ainda estão em diferente medida) marcados com a segregação das pessoas não brancas dos espaços de poder, a exclusão das mulheres das instituições políticas e o não reconhecimento do direito à existência das sexualidades que rompem com a norma cis-heterossexista, além de uma sociedade esmagada pelo monopólio do poder econômico. O avanço dos movimentos sociais se constituiu enquanto principal fator para a ampliação da cidadania, nas lutas do movimento operário, do movimento negro, do movimento feminista e do movimento LGBT.

A partir do século XX, se iniciam as lutas pela descriminalização das homossexualidades, apesar de legitimadas pela enunciação da patologia sexual presente nos primeiros estudos sobre as "inversões sexuais". Os movimentos de homossexuais, lésbicas e transexuais, precursores dos contemporâneos movimentos LGBT, organizados na busca por direitos, ganham força a partir do final da década de 6o, inicialmente na Europa e nos Estados Unidos, conquistando espaço nos mais diversos âmbitos da sociedade e abrindo o caminho para a disputa das políticas estatais (SILVA, 2008), ou seja, das políticas públicas. Consideramos como políticas públicas as ações do Estado que contribuem para a reprodução ou transformação de uma ordem social e política, atuando em termos práticos e simbólico na resolução de uma problemática (CORRÊA, PARKER, 2011), se amparando por legislações e marcos jurídicos, na qual podemos especificar as políticas sociais, diretamente vinculadas à noção de direitos humanos e a constituição de um Estado de Bem-Estar Social, voltadas para a "redistribuição dos benefícios sociais visando a diminuição das desigualdades estruturais" (HÖFLING, 2001: 31). 
A partir da luta dos movimentos feministas e LGBT travadas nos últimos quarenta anos, Jeffrey Weeks (1998) apresenta a emergência de uma cidadania sexual, "rompendo a divisão público/privado que a cultura ocidental há tanto tempo considerou essencial” (p. 36, tradução nossa). A sexualidade, considerada uma esfera privada da vida humana, passa a ganhar espaços dentro dos debates públicos sobre cidadania. É o momento também em que as populações LGBT deixam de virar caso de saúde, sujeitos patologizados, e passam a se constituir enquanto sujeitos políticos, demandantes de cidadania e políticas sociais. Assim, a luta dos movimentos LGBT por uma cidadania sexual passa pela "reivindicação de igualdade de proteção pela lei, por direitos iguais de trabalho, parentalidade, status social, acesso às políticas de bem-estar, e direitos de união estável, ou mesmo o casamento para casais do mesmo sexo" (WEEKS, 1998: 37, tradução nossa).

Entretanto, como aponta João Oliveira (2013), o avanço de neoliberalismo com a propagação do individualismo e da privatização dos espaços públicos, ocasionando o desmonte da noção de Estado de Bem-Estar e das políticas sociais, impõe contradições na constituição da cidadania sexual, dando às pessoas LGBT uma "cidadania de consolação", hierarquizadas pelo poder de consumo e pela normatização heterossexista. Pensarmos em cidadania LGBT nos tempos atuais, é sobretudo pensarmos no recorte interseccional de classe, raça e gênero, e em como os processos de normatização e hierarquização constituem espaços de segregação dentro do próprio segmento LGBT, dentro de um mundo marcado por uma forte crise socioeconômica e política, em que se acirram as polarizações e avançam os discursos fundamentalistas e conservadores.

\section{Políticas Públicas e Direitos LGBT no Brasil}

As movimentações pela redemocratização do país, na década de 80, impactaram as relações entre Estado e sociedade no Brasil, culminando na promulgação da Constituição de 88, que dá ao Estado o papel central na promoção de direitos humanos e de bem-estar social. Sobre a constituição de políticas sexuais, sob forte pressão dos movimentos feministas, temos a criação das primeiras políticas públicas específicas para mulheres, com a criação de Conselhos, da primeira Delegacia de Polícia de Defesa da Mulher, e de Programas de Saúde da Mulher (FARRAH, 2004). Era um momento de efervescência política, abertura democrática e avanço dos movimentos sociais no Brasil, um país que passava por intensas transformações sociais e políticas.

Enquanto o movimento feminista alcançava as primeiras políticas públicas, os movimentos LGBT iniciavam sua trajetória política, com a realização dos primeiros encontros de organizações de homossexuais e das primeiras campanhas, inicialmente voltadas para a afirmação do direito de (r)existência e pela despatologização das homossexualidades, além da construção de uma resposta coletiva à epidemia da AIDS que assolava a comunidade (FACCHINI, 2002; SILVA, 2008). Podemos citar a militância pioneira de organizações como o Grupo Somos/SP, o Grupo Triângulo Rosa/RJ, o Grupo Gay da Bahia, e a veiculação do jornal "O Lampião da Esquina”, editado no Rio de Janeiro. Uma das primeiras vitórias das campanhas promovidas pelos movimentos LGBT, é a apresentação do posicionamento do Conselho Federal de 
Medicina, em 1985 - mais de dez anos após da American Psychiatric Association - defendendo a despatologização das homossexualidades.

Um ocorrido que marca esse momento inicial das lutas por uma cidadania LGBT no Brasil é o discurso de João Mascarenhas, um dos fundadores do Triângulo Rosa/RJ e do Lampião, junto ao Congresso Nacional durante a Assembleia Constituinte, em 1987. Entretanto, a proibição da discriminação por orientação sexual, defendida por Mascarenhas, não é aprovada na Constituição Federal. Iniciaram-se, também na década de 80, as primeiras parcerias entre movimentos LGBT e poder público, na produção de ações em resposta à AIDS, que vieram a consolidar posteriormente um programa estatal, reconhecido internacionalmente, de combate à epidemia.

Os anos 90 são marcados por um processo de institucionalização da militância LGBT em ONG e a ampliação dos coletivos em todo o país, culminando na fundação da ABGLT no Paraná, em 1995, que se dá no mesmo ano da primeira parada do orgulho, realizada no Rio de Janeiro, em decorrência do encontro da ILGA (CARRARA; VIANNA, 2008). É também a partir dessa década que presenciamos uma maior abertura do Estado brasileiro perante a pautas dos movimentos LGBT, com a apresentação e aprovação das primeiras legislações e a criação das primeiras políticas públicas, dando destaque para o Disque Defesa Homossexual, no Rio de Janeiro, em 1999 (CARRARA; RAMOS, 2006). Em relação ao Governo Federal, temos a defesa do combate à discriminação motivada por orientação sexual na Conferência de Durban da ONU, a criação do Conselho Nacional de Combate à Discriminação (CNCD), ambos em 2001, e a publicação do Plano Nacional de Direitos Humanos II com diversas pautas LGBT, em 2002. O CNCD era composto por representantes dos movimentos LGBT e se tornou o principal interlocutor desse grupo social com o Governo Lula (2003-2010), contribuindo de forma essencial para a criação do Programa Brasil Sem Homofobia (ITABORAHY, 2012).

O Brasil passa por transformações socioculturais significativas no tocante às políticas sexuais e, nos anos 2000, presenciamos o avanço das pautas LGBT em diversas esferas da sociedade brasileira e a constituição de uma ampla rede política, aglutinando partidos políticos, movimentos sociais, ONG, meios de comunicação, parlamentares, gestores, grupos acadêmicos, entre outros. As paradas do orgulho se expandem em tamanho e quantidade, como uma estratégia de visibilidade massiva, se tornando em pouco tempo as maiores manifestações de rua de um movimento social brasileiro. Temos também a consolidação de um forte mercado GLS, em diversos momento integrado à militância. Assim, o reconhecimento da cidadania sexual de pessoas LGBT vai ganhando espaço na sociedade brasileira, ainda marcada pela discriminação e pela violência. Esse reconhecimento é reafirmado pelo Governo Federal com a apresentação do Programa Brasil Sem Homofobia, em 2004, iniciativa pioneira no mundo de sistematização de propostas políticas e ações governamentais para a população LGBT.

O Brasil Sem Homofobia (BSH), apesar de todas as dificuldades em sua implementação efetiva (FROEMMING; IRINEU; NAVAS, 2010), impulsionou novas relações entre o Estado brasileiro e as políticas LGBT, assim como a assimilação de parte da militância dentro da máquina estatal e da gestão de políticas públicas. A criação de Centros de Referência LGBT em todo o país, uma ação prevista pelo BSH iniciada em 2006, foi realizada em sua grande maioria a partir de parcerias com ONG, em que o governo era responsável pelo financiamento e o movimento pela gestão da política, contribuindo para a 
constituição de laços entre o poder público local e parte do movimento. Entretanto, essa política não teve continuidade, ficando a cargo do poder público local a decisão de mantê-la ou não, ocasionando o fechamento da maioria dos Centros de Referência em poucos anos.

O período de 2004 a 2010 foi de grande expansão das políticas em nível nacional, na qual podemos citar a realização da I Conferência Nacional LGBT (2008), a regulamentação do processo transexualizador no âmbito do SUS (2008), a criação do Plano Nacional LGBT (2009), a divulgação do Programa Nacional de Saúde Integral LGBT (2010), e a criação do Conselho Nacional LGBT (2010), além de uma série de ações menores. Ao final da gestão Lula (2003-2010), o Governo Federal se apresentou como o impulsionador do que podemos chamar de " melhor conjunto de propostas de políticas para transexuais, travestis, bissexuais, gays e lésbicas em todo o mundo" (MELLO; MAROJA; BRITO, 2010: 56), políticas iniciadas pelo governo anterior e consolidadas pela pressão dos movimentos LGBT e sua ampla rede política.

Entretanto, muitas delas permanecem apenas como propostas e as dificuldades na sua implementação são grandes, principalmente pela força política dos movimentos conservadores e anti-LGBT em nossa sociedade. Isso é demonstrado nos entraves enfrentados no Congresso Nacional para a aprovação de políticas LGBT, em que projetos legislativos que vinham sendo debatidos desde a década de 90, como a criminalização da homofobia e o casamento homoafetivo, foram sistematicamente barrados e inviabilizados. Atualmente não existe uma única legislação aprovada em nível nacional e os retrocessos no Plano Nacional de Educação, em 2014, deram sinais que o cenário político tendia a se agravar.

A suspensão do material do Programa Escola Sem Homofobia, intitulado kit-gay pela bancada conservadora no Congresso Nacional, no início de 2011, representou o início do recuo do Governo Federal na implementação de políticas públicas LGBT. Era o início do primeiro mandato do Governo Dilma (2011-2014), que na costura da governabilidade cedeu às pressões dos setores conservadores da política que estavam em plena ascensão no cenário nacional. Entretanto, tivemos algumas políticas importantes, como a realização da II Conferência Nacional LGBT (2011), a criação do Sistema Nacional LGBT e do Comitê Nacional de políticas públicas LGBT (2013), e da Comissão Interministerial de Enfrentamento à Violência contra LGBT (2015). Porém, existe uma grande fragilidade na efetivação de tais políticas por não se apresentarem enquanto prioridades governamentais. Em meio a esse cenário de retrocessos, duas grandes vitórias foram alcançadas por meio do Judiciário Federal, o reconhecimento da união civil (2011) e do casamento homoafetivo (2013), lembrando que, em 2010, o Superior Tribunal de Justiça reconheceu a legalidade das adoções por casais homoafetivos.

Apesar dos últimos cinco anos terem sido marcados por retrocessos nas políticas do Governo Federal, tivemos também a descentralização das políticas LGBT dos grandes centros (Rio-São Paulo) e sua expansão para todas as regiões do Brasil, vinculadas aos poderes municipais e estaduais, com a criação de órgãos específicos, conselhos, programas, planos, e com o avanço de legislações. No entanto, o cenário político atual é marcado por grande instabilidade, como demonstrado, em 2015, com a derrubada do debate sobre orientação sexual e identidade de gênero da maioria dos (se não todos) planos municipais e estaduais de educação - seguindo a onda do avanço do fundamentalismo 
religioso cristão e do conservadorismo político, as articulações das igrejas católicas e evangélicas em torno da luta contra a "ideologia de gênero", e a derrubada do debate LGBT no Plano Nacional de Educação, em 2014. As políticas públicas LGBT seguem com bases frágeis para se manterem sob implementação contínua e efetiva.

Vivemos um período de estreitamento da agenda política LGBT no Brasil, porém devemos relembrar o que é o Estado e suas delicadas relações de poder, e qual é a relação da máquina pública com as movimentações da sociedade civil, além de nos atentarmos para a evolução dos setores políticos que hoje barram as pautas LGBT, para assim pensarmos em estratégias visualizando a superação do atual cenário político de fundamentalismo cristão e conservadorismo político, em meio à uma das maiores crises político-institucionais da história da república brasileira e da atual crise mundial do sistema capitalista.

\section{(Des)caminhos da Cidadania LGBT em Mato Grosso}

O Estado de Mato Grosso, localizado na região Centro-Oeste do Brasil, na divisa com a Bolívia e a região Norte, é nacionalmente conhecido por sua produção agrícola e pecuária que abastece o mercado internacional. Em seu histórico, Mato Grosso esteve dentro dos projetos governamentais de povoamento do interior do Brasil, apresentando um boom de crescimento populacional, nas décadas de 70 e 80, impulsionado pelas contraditórias políticas do Governo Militar, que se refletem atualmente na alta concentração de terras e na sistemática destruição de povo tradicionais (indígenas e quilombolas) e do meio ambiente. Em suma, é um estado de imensidão territorial, sendo a terceira maior unidade federativa do país e a terceira menos povoada, com uma econômica centrada na exportação de produtos agropecuários. Podemos citar, das principais áreas urbanas de MT, a região metropolitana de Cuiabá (municípios de Cuiabá e Várzea Grande), os municípios de mais de cem mil habitantes, Sinop (região norte do estado) e Rondonópolis (sudeste), e os municípios menores de Cáceres (centro-sul) e Tangará da Serra (sudoeste).

Mato Grosso, assim como outras regiões do interior do Brasil, também é conhecido pelo monopólio do poder econômico e político por grupos oligárquicos e por graves denúncias de violação de direitos humanos, principalmente relacionadas a conflitos territoriais, ambientais e agrários (SATO; WERNER; ROSSI, 2013). A violência urbana também se faz presente, afetando diretamente grupos historicamente oprimidos, violados nos direitos básicos assegurados pela Constituição, como mulheres, a população negra, indígena e LGBT. Neste sentido, não é surpresa que a promoção de direitos humanos não seja prioridade nas políticas estatais em um cenário políticoinstitucional estadual majoritariamente conservador. Os partidos de tradição de esquerda e os movimentos sociais possuem pouca capilaridade e base social, aliando-se a isso, é marcante a forte repressão e intimidação a qualquer tipo de movimentação que transgrida a ordem social. Em meio a esse cenário social e político, a pauta LGBT encontrou dificuldades em adentrar no debate das políticas públicas e podemos dizer que atualmente estamos retrocedendo e perdendo alguns espaços importantes conquistados nos últimos dez anos. Como exemplo do difícil cenário para a implementação de políticas públicas LGBT em Mato Grosso, podemos relembrar a votação pelo apensamento do PLC 122/o6, que criminaliza a homofobia, ao Projeto do Novo Código Penal (PL 236/12), em 
dezembro de 2013, na prática "enterrando-o politicamente". Os dois senadores de MT, figuras influentes no cenário estadual, que votaram pelo enterramento do projeto eram nada menos que o ex-governador, Blairo Maggi, e o atual governador, Pedro Taques.

Para termos uma percepção desse recuo estadual nas políticas LGBT, podemos utilizar como parâmetro de análise os Planos Plurianuais (PPA) do Governo do Estado, apesar de sabermos que nem sempre o previsto nos planos se torna política implementada. A promoção de cidadania e direitos LGBT é pautada pela primeira vez no PPA 2008-2011, durante o segundo mandado de Blairo Maggi (PR), governador de 2003 a 2010. Os programas vinculados às questões LGBT, apresentados em conjunto com as questões étnico-raciais, totalizaram uma previsão orçamentária de quase $\mathrm{R} \$ 10$ milhões. Na gestão seguinte, de Silval Barbosa (PMDB), PPA 2012-2015, foi apresentada uma previsão orçamentária específica para a promoção da cidadania LGBT totalizando aproximadamente $\mathrm{R} \$ 2$ milhões, mantendo certa continuidade em relação à gestão anterior. O PPA 2016-2018, da gestão de Pedro Taques (PSDB), não faz nenhuma referência à população LGBT, demarcando um sério retrocesso em relação aos PPA anteriores, provavelmente devido à pressão de setores conservadores que ganharam espaço na política matogrossense nas últimas eleições.

Os movimentos LGBT em Mato Grosso, que propiciaram o avanço das políticas LGBT no estado, iniciaram sua trajetória na década de 90, tendo como marco histórico a fundação do grupo Livre-Mente, em 1995 (IRINEU, 2008; LOPES, 2014). O Livre-Mente marcou profundamente a história do ativismo LGBT do estado, se tornando o centro do qual emergiram outras ONG na Baixada Cuiabana: a Associação das Travestis de Mato Grosso (ASTRAMT), em Várzea Grande, a Associação pela Liberdade Lésbica (LIBLES) e o Grupo de Afrodescendentes pela Livre Orientação Sexual (GRADELOS), ambos em Cuiabá - criadas enquanto núcleos identitários dentro da ONG Livre-Mente, se instituindo como ONG autônomas, respectivamente em 2003, 2004 e 2006. Ao longo dos anos, foram organizados outros coletivos no interior do estado, em municípios como Sinop, Cáceres e Rondonópolis, na qual damos destaque para o Coletivo de Diversidade Sexual do Sindicato dos Trabalhadores do Ensino Público de Mato Grosso (SINTEP-MT), aglutinando pessoas de diversas regiões do estado.

As Paradas da Diversidade também são um marco importante para a militância em Mato Grosso, com a realização da primeira em 2003, reunindo cerca de duas mil pessoas. A parada de Cuiabá é realizada anualmente, sendo a maior manifestação periódica de um movimento social no estado, reunindo em seu ápice, na edição de 2007, mais de dez mil pessoas. No entanto, também já foram realizadas paradas nos municípios de Várzea Grande, Rondonópolis e Cáceres, além da parada do bairro Pedra 90, na periferia de Cuiabá. Nos últimos cinco anos, os movimentos LGBT matogrossenses passaram por um processo de refluxo e atualmente se rearticulam, e se renovam, principalmente em torno da organização do Conselho Municipal LGBT de Cuiabá e do reagrupamento do Livre-Mente.

Sobre o histórico das políticas LGBT em Mato Grosso, temos, em 2007, a criação do que podemos considerar como a primeira política pública para a população LGBT no estado, com a criação dos Centros de Referência em Direitos Humanos e Prevenção e Combate à Homofobia (CR-LGBT), um em 
Cuiabá e outro em Rondonópolis. Apesar da Constituição Estadual de 89 definir a asseguração de que ninguém será prejudicado (ou privilegiado) com base na orientação sexual, seus efeitos foram praticamente nulos para a construção de políticas LGBT no estado. A criação dos Centros de Referência LGBT foi possível graças ao edital da Secretaria Especial de Direitos Humanos da Presidência da República (SEDH-PR), que destinava recursos financeiros para essa finalidade, em parcerias com órgãos públicos ou sociedade civil, sendo uma ação do Brasil Sem Homofobia. No caso de Cuiabá, o Centro LGBT foi gerenciado pelo Governo do Estado, e o de Rondonópolis pela ONG Vida Ativa. Os CR-LGBT, enquanto existiram, executaram diversas ações voltadas ao público LGBT e abriram caminhos para a sensibilização de parte do poder público para a necessidade de implementação de políticas e cidadania LGBT. O Centro de Referência, em Rondonópolis, fechou após dois anos com dificuldades de funcionamento e gestão, e o de Cuiabá foi incorporado, em 2012, ao recém criado Centro de Referência em Direitos Humanos (CRDH).

As Conferências Estaduais LGBT também se apresentaram enquanto um marco na construção de uma cidadania LGBT e da articulação da militância em Mato Grosso, contando com grande participação de pessoas e mobilizando debates em diversas regiões do estado em suas duas primeiras edições, em 2008 e 2011, apresentando certo refluxo e maior dificuldade organizativa na terceira edição, em 2016. Sobre as políticas implementadas durante esse período, no âmbito da educação, temos a criação da Gerência de Diversidades da Secretaria de Estado de Educação (SEDUC), que publica, em 2009, um caderno sobre diversidade sexual na escola; e a instituição do nome social de travestis e transexuais em registros acadêmicos (com exceção do diploma e histórico escolar), naquele mesmo ano, pelo Conselho Estadual de Educação. Em 2011, a Universidade Federal de Mato Grosso aprova medida similar. No âmbito da segurança pública, temos a criação do Grupo Estadual de Combate à Homofobia (GECCH), em 2012, que continua em atividade, acompanhando casos de violência contra LGBT, realizando formações entre agentes públicos e buscando aberturas institucionais para a aprovação de políticas LGBT. Dentro de algumas esferas do poder executivo, o $\mathrm{CECCH}$ conseguiu a aprovação de portarias referentes à regulamentação do nome social. E, por fim, outra política dentro da segurança pública, mais especificamente no sistema penitenciário, é a criação da Ala LGBT no Centro de Ressocialização de Cuiabá, em 2011, apesar de ainda carecer de regulamentação.

Existem algumas legislações aprovadas para a população LGBT em Mato Grosso, porém apenas em nível municipal. Os dois projetos legislativos de abrangência estadual, a instituição do dia estadual de combate à homofobia (2007) e a criminalização da homofobia (2007), não conseguiram avançar na Assembleia Legislativa. No entanto, em 2007, em meio a um momento de crescimento do movimento LGBT em Mato Grosso, tivemos a aprovação das primeiras leis: o Dia Municipal Contra a Homofobia em Cuiabá e Rondonópolis. No ano seguinte, foi acrescentada ao estatuto dos servidores públicos de Cuiabá a proibição da discriminação de pessoas LGBT e, em 2012, a proibição de "toda e qualquer forma" de discriminação baseada na orientação sexual em Cuiabá, sendo projetos legislativos do Vereador Lúdio Cabral (PT). A lei que proíbe a discriminação contra pessoas LGBT em Cuiabá, até o momento, não foi regulamentada pelo poder executivo, demarcando o descaso do governo municipal e praticamente inviabilizando sua aplicação. Há também notícias de 2013 sobre a aprovação de uma legislação, em Várzea Grande, legitimando a 
utilização do nome social de travestis e transexuais em estabelecimentos públicos e privados do município, porém não há informações sobre sua efetivação. O Conselho Municipal LGBT de Cuiabá foi criado por meio de projeto de lei, em 2014, enviado pelo poder executivo. E atualmente há um projeto, em tramitação na Assembleia Legislativa, buscando a regulamentação da presença de travestis e mulheres transexuais em presídios femininos, dentre outras medidas relacionadas também a homens transexuais.

Como apresentado anteriormente, o ano de 2015 foi marcado por dois grandes retrocessos vinculados ao poder legislativo - a retirada do debate de gênero e sexualidade do Plano Municipal de Cuiabá, na Câmara de Vereadores, e a derrubada do decreto de criação do Conselho Estadual LGBT, pela Assembleia Legislativa - em um momento de marcante polarização política e intensificação de uma militância anti-LGBT no estado. A última gestão governamental, de Silval Barbosa (2010-2014), também era apresentada como desfavorável para as políticas LGBT, principalmente pela resistência na criação do Conselho Estadual. A gestão seguinte, de Pedro Taques (2015-2018), apresenta o decreto de criação do conselho, em setembro de 2015, no entanto, no mês seguinte a Assembleia Legislativa aprova sua derrubada, apoiada por igrejas evangélicas e católicas, reafirmando o momento nada favorável para a aprovação de políticas LGBT no estado, acompanhando os retrocessos que presenciamos nacionalmente.

\section{Conclusões}

Apresentamos ao longo do artigo um cenário político de estreitamento da agenda LGBT no Brasil, que se inicia partir de 2011 e se intensifica em 2015, tendo seus reflexos nas políticas públicas em Mato Grosso, em um momento de refluxo dos movimentos LGBT locais, apesar de suas recentes tentativas de rearticulação. De forma paralela, presenciamos o crescimento do fundamentalismo cristão e sua reorganização política, buscando espaços institucionais para a promoção de políticas sexuais conservadoras e a deslegitimação de direitos e políticas públicas destinadas à população LGBT.

O avanço das políticas sexuais e da cidadania LGBT no cenário políticoestatal brasileiro nos últimos quinze anos - da publicação do PNDH II, em 2002, e do Brasil Sem Homofobia, em 2004, aos dias atuais - encontra seu momento de estagnação, ou a marcação do fim de um ciclo. Vivemos um momento de reação conservadora contra tais avanços, em uma conjuntura bastante desfavorável para a noção de direitos humanos de forma geral. Algo que se inicia em 2011, com o pânico moral gerado, no Congresso Nacional, pelo vazamento dos materiais do Programa Escola Sem Homofobia, ocasionando sua suspensão praticamente imediata pelo Governo Federal. Uma reação que ganha fôlego com a conquista da presidência da Comissão de Direitos Humanos e Minorias da Câmara dos Deputados pelo pastor ultraconservador Marcos Feliciano (PSC/SP), em 2013, e atualmente toma proporções aterradoras e praticamente domina o cenário político nacional. Ainda não vivemos a possibilidade do fim da cidadania LGBT no Brasil, mas os presentes retrocessos não devem ser de forma alguma minimizados e servem de alerta para o poder político crescente daqueles que desejam o fim de um Estado promotor de direitos humanos e sociais e, sobretudo, de direitos LGBT. 
Quais os caminhos que devemos percorrer para a continuidade das políticas públicas de cidadania LGBT? Como apresentamos anteriormente, a disputa da sociedade civil é uma esfera fundamental para a disputa das políticas estatais. Os movimentos sociais foram uma peça fundamental para a conquista de direitos e cidadania no Brasil, e o fortalecimento e a rearticulação dos movimentos LGBT é uma parte essencial desse caminho que, pouco a pouco, se estreita.

\section{Referências Bibliográficas}

BEHRING, Elaine R. Fundamentos de Política Social. In: MOTA, A. E. et al. (org.). In: Serviço Social e Saúde: formação e trabalho profissional. São Paulo: OPAS, OMS, Ministério da Saúde, 2006.

BORRILLO, Daniel. Homofobia: história e crítica de um pensamento. Belo Horizonte: Autêntica Editora, 2010.

BRASIL. Câmara dos Deputados. Pronunciamento Encaminhado à Mesa para Publicação. Brasília: DEATQ, 2016. Disponível em: http://goo.gl/aXFn3Y. Acessado em 06/04/16.

CARRARA, Sérgio; RAMOS, Silvia. A Constituição da Problemática da Violência contra Homossexuais: a Articulação entre Ativismo e Academia na Elaboração de Políticas Públicas. PHYSIS: Rev. Saúde Coletiva, Rio de Janeiro, v. 16, n. 2, 2006, p. 185-205.

; VIANA, Adriana R. B. Políticas Sexuales y Derechos Sexuales en Brazil: estudio de caso. In PARKER, R.; PETCHESKY, R.; SEMBER, R. Políticas sobre Sexualidad: Reportes desde líneas del frente. Sexuality Policy Watch, 2008.

CONNELL, Raewyn V. The State, Gender, and Sexual Politics: Theory and Appraisal. Theory and Society, v. 19, n. 5, 1990, p. 507-544.

CORREAA, Sonia; PARKER, Richard (org.). Sexualidade e política na América Latina: histórias, interseções e paradoxos. Rio de Janeiro: ABIA, 2011.

COSTA, Carolina R.; SIMIONATTO, Ivete. Estado, Luta de Classes e Política Social. In: OLIVEIRA, Mara; BERGUE, Sandro T. (org.). Políticas Públicas: definições, interlocuções e experiências. Caxias do Sul, RS: Educs, 2012.

COUTINHO, Carlos N. Notas sobre Cidadania e Modernidade. São Paulo: Cortez, 2000.

ensaios. São Paulo: Cortez, 2008.

Marxismo e Política: a dualidade de poderes e outros

DEPARTAMENTO INTERSINDICAL DE ASSESSORIA PARLAMENTAR. Radiografia do Novo Congresso Nacional: Legislatura 2015-2019. Brasília, DF: DIAP, 2014. 
FACCHINI, Regina. "Sopa de Letrinhas"? - movimento homossexual e produção de identidades coletivas nos anos 90: um estudo a partir da cidade de São Paulo. Dissertação de Mestrado. Campinas: Instituto de Filosofia e Ciências Humanas, UNICAMP, 2002.

FARAH, Marta F. S. Gênero e políticas públicas. Estudos Feministas, Florianópolis, v. 12, n. 1, jan.-abr., 2004.

FOUCAULT, Michel. História da sexualidade I: A vontade de saber. Rio de Janeiro: Edições Graal, 1988.

FROEMMING, Cecilia. N.; IRINEU, Bruna. A.; NAVAS, Kleber. Gênero e Sexualidade nas pautas das políticas públicas no Brasil. São Luís, Revista de Políticas Públicas, número especial, 2010, p. 116-172.

HERZFELD, Michael. Cultural Intimacy: Social Poetics in the Nation-State. New York/London: Routledge, 1997.

HÖFLING, Eloisa M. Estado e Políticas (Públicas) Sociais. Cadernos Cedes, ano XXI, n. 55, nov. 2001.

IRINEU, Bruna A. Narrativas da (In)Diferença: um estudo sobre as políticas públicas de segurança pública no combate a homofobia em Mato Grosso. Monografia de especialização. Cuiabá: Instituto de Ciências Humanas e Sociais, UFMT, 2008.

. Homonacionalismo e cidadania LGBT em tempos de neoliberalismo: dilemas e impasses às lutas por direitos sexuais no Brasil. Revista Em Pauta, Rio de Janeiro, n. 34, v. 12, 2014, p. 155-178.

ITABORAHY, Lucas P. LGBT Rights in Brazil: An Analysis of the public policies established by the Federal Government to recognize the human rights of the LGBT community. Dissertação de mestrado. University of Gothenbur, Roehampton University, University of Tromso, 2012.

LOPES, Moisés. O movimento LGBT da Baixada Cuiabana e a segmentação de identidades. Algumas questões para reflexão e debate. Anais do III Simpósio de Gênero e Políticas Públicas. Londrina, 2014.

MARSHALL, T. H. Citizenship and Social Class. In. MARSHALL, T. H.; BOTTOMORE, T. Citizenship and Social Class. London: Pluto Press, 1992.

MELLO, Luiz; MAROJA, Daniela; BRITO, Walderes. Políticas Públicas para população LGBT no Brasil: um mapeamento crítico preliminar. Relatório de Pesquisa. Goiânia, UFG, Faculdade de Ciências Sociais, Ser-Tão, Núcleo de Estudos e Pesquisa em Gênero e Sexualidade, 2010

OLIVEIRA, João M. Cidadania sexual sob suspeita: uma meditação sobre as fundações homonormativas e neo-liberais de uma cidadania de "consolação". Psicologia \& Sociedade, v. 25, n. 1, 2013, p. 68-78. 
RUBIN, Gayle. Thinking sex: notes for a radical theory of the politics of sexuality. In Carole S. Vance (org.). Pleasure and danger: exploring female sexuality. Londres: Routledge e Kegan Paul, 1984. p. 267-319.

SATO, Michele; WERNER, Inácio; ROSSI, Roberto (Org.). Relatório de Direitos Humanos. Cuiabá: DTH/Centro Burnier Fé e Justiça, 2013.

SCOTT, Joan W. Gender: a Useful Category of Historical Analysis. The American Historical Review, v. 91, n. 5, dez. 1986, p. 1053-1075.

SILVA, Alessandro S. Luta, Resistência e Cidadania: uma análise psicopolítica dos Movimentos e Paradas do Orgulho LGBT. Curitiba: Juruá, 2008.

WEEKS, Jeffrey. The Sexual Citizen. Theory, Culture \& Society, v. 15, n. 3, 1998, p. 35-52.

Sexuality and its discontents: meanings, myths \& modern sexualities. New York: Routledge, 2002.

WELZER-LANG, Daniel. A construção do masculino: dominação das mulheres e homofobia. Revista Estudos Feministas, Florianópolis, v. 9, n. 2, 2001. 